\title{
A STUDY ON GLASS FIBER REINFORCED POLYMER-CLAY NANOCOMPOSITES WITH SANDWICH STRUCTURE
}

\author{
Shivraj Puggal ${ }^{1}$, Sumit Mahajan², Novepreet Dhall ${ }^{3}$ \\ ${ }^{1}$ Department of Mechanical Engineering, Lovely Professional University, Punjab, India \\ ${ }^{2}$ Department of Mechanical Engineering, Lovely Professional University, Punjab, India \\ ${ }^{3}$ Department of Mechanical Engineering, Lovely Professional University, Punjab, India
}

\begin{abstract}
Glass fiber reinforced polymer (GFRP) has been found attractive due to high strength-to-weight ratio, high stiffness-to-weight ratio, and corrosion and fatigue resistance. The properties of GFRP are further enhanced by adding very small amount of nanometer size particles. The use of sandwich composites with GFRP face sheets is becoming popular in structural design because of their ability to substantially decrease weight while maintaining mechanical performance. In this study face sheets of sandwich composites are modified using nanoclay particles. The sandwich structure composed of bidirectional E-glass fiber, Closite 30B nanoclay, epoxy resin and high density thermocol. Hand layup method was used for fabrication of sheets also the nanoclay percentage was varied subjected to various test. The use of nano composite increases the bending strength up to $41 \%$ as compared to virgin epoxy. The natural degradation of bending specimen with neat epoxy showed the maximum degradation up to $10 \%$ and it was $5 \%$ in case of specimens with nano composite sheets. The water resistance property of epoxy was improved by the addition of both glass fibre and nanoclay. The tensile strength is raised by 33\% by using 3\% of clay in the epoxy. The SEM and $X R D$ were performed for characterization of the nano composites.
\end{abstract}

Keywords: Nanocomposites, Sandwich structure, Bending strength, and Natural degradation.

\section{INTRODUCTION}

Sandwich composites are a specialized form of laminated composites in which a thick, soft and light weight core is sandwiched between two thin and stiff fiber reinforced plastic skins (1). The use of light core reduces the weight so this weight reduction results in a number of benefits, including increased range, higher payloads and decreased fuel consumption. All have a positive impact on cost as well as a decreased impact on the environment. Desired properties can be produced by modifying face sheets or core material. The sandwich structure composed of GFRP face sheets and thermocol core showed that higher thickness core withstands a higher bending load showing less flexural stress and flexure modulus(2). Aluminum composite made by using Aluminum skin, polyethylene core and epoxy resin is light and strong as compared to aluminum panel. Weight reduction and lesser heat infiltration were observed by using aluminum composite (3). The face sheets can be amended using the nanocompoites as it produces various property enhancements. Rajmohan concluded that the increase in wt $\%$ of nano Copper oxide improves the mechanical properties mainly due to the very large surface area of interaction between polymer matrix and nano filler (4). The proper dispersion montmorillonite clay in the epoxy resin produces higher compressive stiffness compared to neat polymer. The presence of agglomerates in epoxy reduces the compressive strength so clay should be properly dispersed (5). B. Sharma used hand lay-up method for preparing fiber reinforced nanocomposites and agglomerates were visible when $5 \%$ clay was added. Tensile strength and micro- hardness increases with addition of nanoclay up to $3 \mathrm{wt} \%$ (6).

\section{MATERIALS AND MANUFACTURING}

The materials used in this study were Bidirectional E-glass fibers, Lapox a two part epoxy resin purchased from Atul Polymers (India) Private, High density thermocol of thickness $16 \mathrm{~mm}$ and organically modified nanoclay Closite 30B purchased from Nano shell India.

\subsection{Dispersion of Nanoclay into Base Epoxy}

First the base epoxy and required amount of nanoclay is measured with help of digital weighing machine. Epoxy base L-12 is a transparent thick fluid. It is quite difficult to mix nanoclay into it manually. As powder nanoparticles adhere to each other due to interactive forces between the particles, resulting in nanoparticle agglomerates with dimensions of several micrometers. So we used a homogeniser having RPM 2000 and a magnetic hot plate for proper mixing of nanoclay. Hot plate was used to heat up the base epoxy to desired temperature $\left(60^{\circ}\right)$, so the viscosity of epoxy is reduced as shown in Figure 1. Proper mechanical stirring of epoxy at this stage resulted better scattering of clay. The process of heating as well as stirring was performed, concomitantly for 2 hours to ensure the better dispersion to avoid agglomerates formation in the base epoxy. The amount of nanoclay dispersed into the epoxy system, in weight, is $1 \%, 3 \%$ and $5 \%$ respectively. 


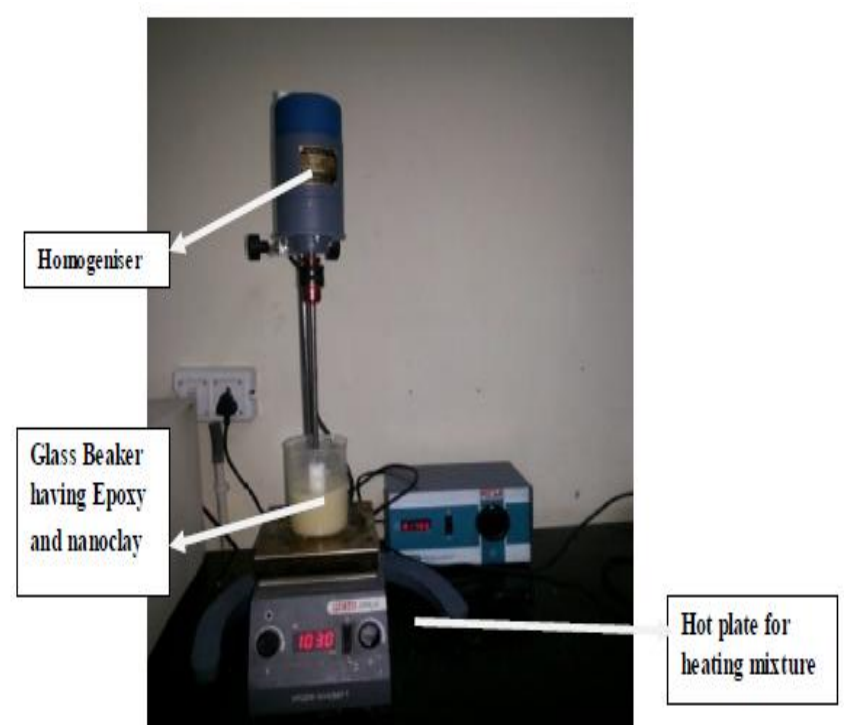

Fig-1: Set up for mixing clay in epoxy

\subsection{Preparation of Epoxy Resin for GFRP} Composites Fabrication

After mechanical stirring of the epoxy solution container was placed into the ultra sonication bath for up to 2 hours. During sonication sound energy is used to whisk particles for evenly dispersing nanoparticles in liquids. After ultra sonication, the solution is mixed with the hardener in the ratio 10:1 by volume. After mixing, manual stirring up to 5 to 10 minutes was done such that the hardener mixes properly in modified epoxy. The pot life of mixture is $15-20$ minutes at ambient temperature.

\subsection{Coating of Nanoclay Mixed Epoxy to Glass}

\section{Fiber Sheets}

The mixture was then poured on to the glass fibre mat and applied uniformly using the hand layup method. For this, steel scraper was used to maintain consistency of the solution. The full curing of sheet was done by leaving it under ambient temperature for one day before processing further.

\subsection{Sizing of Sheet for Specimen}

The specimen had been cut and prepared as per the ASTM standard C-393 for bending and D3037/3039 for tensile. The samples had to be tabbed on either side on two ends for tensile testing. For the three point bending test the use of high density thermocol was used and placed between two face sheets of nano composites.

\section{EXPERIMENTAL PROCEDURES}

\subsection{Characterization Techniques}

X-ray diffraction was used to scrutinize the changes that occur to the clay due to the intercalation and/or exfoliation of the epoxy into the clay galleries. The measurements were carried out in a X-ray diffractometer with $\mathrm{Cu} \mathrm{K} \alpha$ radiation at $\lambda=1.54 \AA$ with a scanning speed of $1 \%$ min and operating at
$45 \mathrm{kV}$ and 40. A scanning electron microscope (SEM) is a type of electron microscope that produces images of a sample by scanning it with a focused beam of electrons. The polishing of specimen was done by using Gold coating equipment. The polished specimen was used to contemplate clay dispersion at different magnification.

\subsection{Flexural Testing Analysis}

The Three Point Bending flexural test provides values for the flexural stress $\sigma_{\mathrm{f}}$, flexural strain $\varepsilon_{\mathrm{f}}$ and the flexural stressstrain response of the material. The main advantage of a three point flexural test is the ease of the specimen preparation and testing. Three point bending tests of specimen were carried out in using Zwick / Roell. Flexural stress for rectangular cross sections given by

$$
\sigma_{\mathrm{f}=} 3 P L / 2 b d^{2}
$$

\subsection{Tensile Testing Analysis}

The test specimen for tensile testing had been prepared according to ASTM-D-3039 standard. The specimens were tested on universal testing machine until they break stipulating the peak load and ultimate stress value they can bear at required time period.

\subsection{Weight Gain Analysis}

The specimens of various clay loadings were dunked in water at environmental temperature. The percentage weight gain at any time $\left(\mathrm{W}_{\mathrm{t}}\right)$ as a result of moisture absorption was determined by eq. (1)

$$
\mathrm{W}_{\mathrm{t}}=\left(\mathrm{W}_{\mathrm{w}}-\mathrm{W}_{\mathrm{d}}\right) / \mathrm{W}_{\mathrm{d}} \times 100
$$

Where $\mathrm{W}_{\mathrm{d}}$ and $\mathrm{W}_{\mathrm{w}}$ denote the weight of dry material prior to exposure and weight of materials after exposure to natural degradation.

\section{RESULTS AND DISCUSSION}

The X-ray diffraction (XRD) was used to discern the dspacing and corresponding intensity of the samples having different nanoclay loading. The diffraction peak of Closite $30 \mathrm{~B}$ nanoclay is visible at $2 \theta=4.81^{\circ}$ having interlayer spacing $18.42 \AA$. The results of various specimens of different loading showed that d-spacing of layers increased from $18.42 \AA$ to $32.32 \AA$ Table 1 showing comparison for various clay loadings and thus confirmed intercalation of clay particles. This is due to the penetration of polymer chains in between layered silicates which increases there spacing.

Table -1: XRD results for various clay loadings

\begin{tabular}{|l|l|l|l|}
\hline S.No & $\begin{array}{l}\text { CLAY } \\
\text { LOADING }\end{array}$ & $2 \theta$ & d-spacing $\AA$ \\
\hline 1 & $1 \%$ & 3.6513 & 24.1791 \\
\hline 2 & $3 \%$ & 2.8545 & 30.9262 \\
\hline 3 & $5 \%$ & 2.7308 & 32.3263 \\
\hline
\end{tabular}


The SEM images were used for the investigation of the dispersion state of nanoclay particles in the epoxy and were carried out at various magnifications. Some of the Scanning electron micrographs are shown in Figures 1, 2 and 3. The SEM micrographs have shown very good dispersion in case of $1 \%$ and $3 \%$ however presence of agglomerates were recognizable in $5 \%$ specimen.

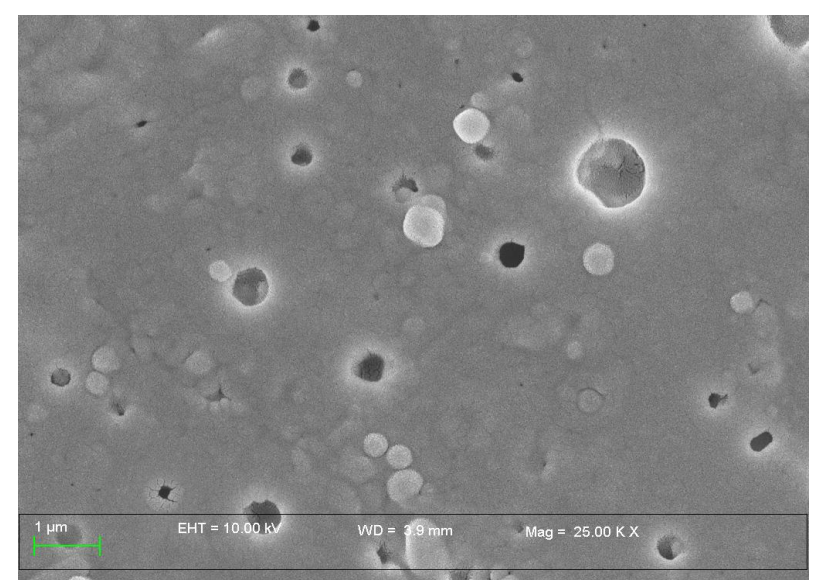

Fig-2: SEM image of epoxy with $1 \%$ clay at $25 \mathrm{KX}$

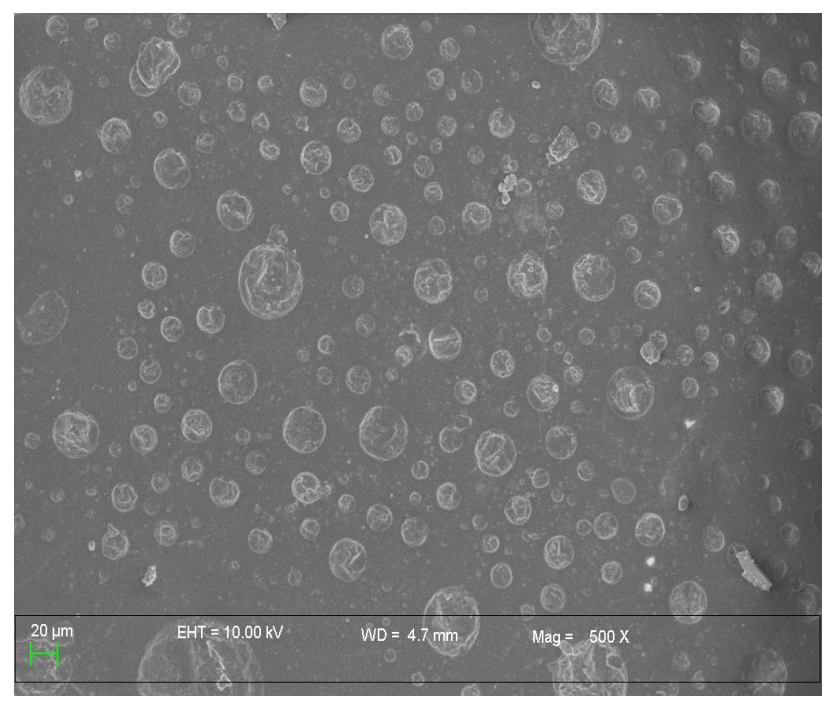

Fig-3: SEM image of epoxy with $3 \%$ clay at $25 \mathrm{KX}$

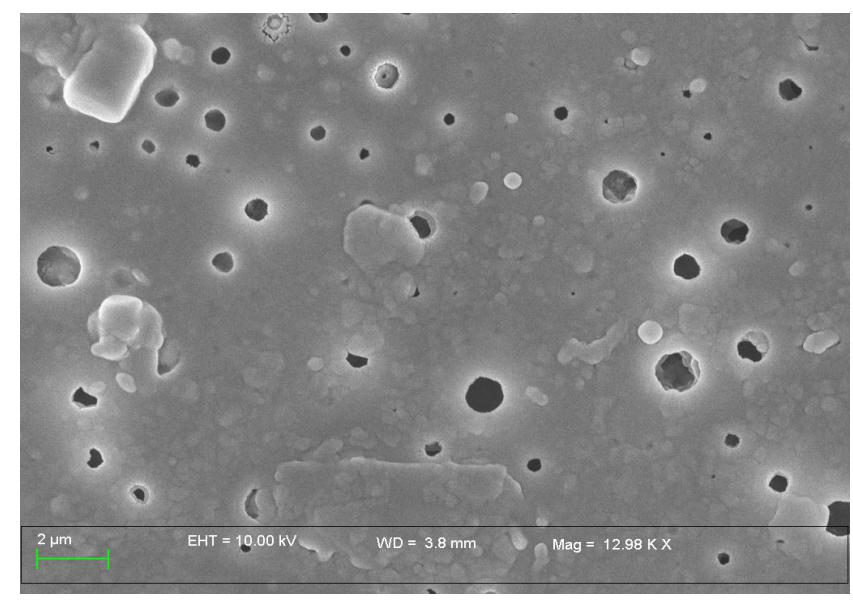

Fig-4: SEM image of epoxy with $5 \%$ clay at $25 \mathrm{KX}$
The tensile test was conducted for all the specimens and specimen without nanoclay was used as bench mark. The tensile strength increased $33 \%$ by the addition of nanoclay particles in epoxy. The maximum tensile strength is achieved by using $3 \%$ of clay and further addition reduced the strength as shown in figure 5 . The stress concentration is the main reason for the reduction in tensile strength which is due to agglomerates as visible in SEM images.

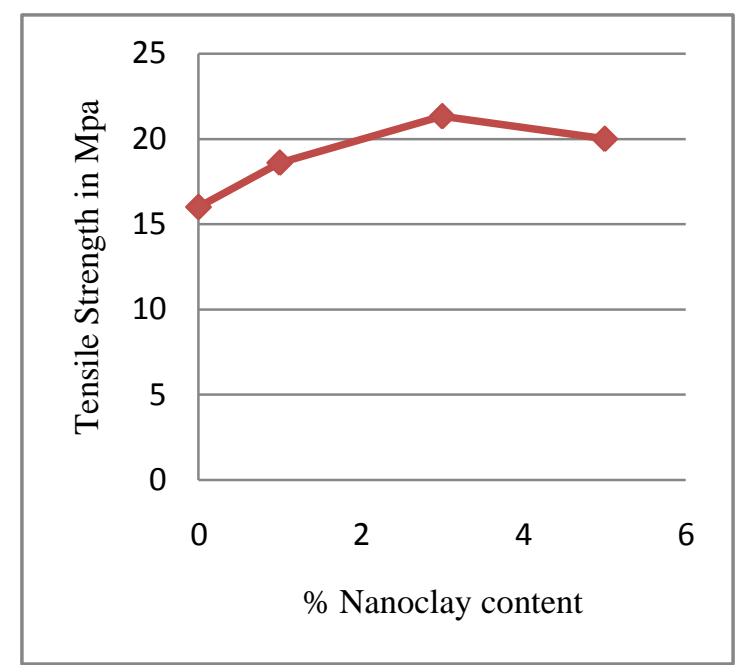

Fig-5: Tensile strength MPa of nanocomposite at different clay loadings

In the specimens of various clay loading were tested under three point bending test. The result of bending test showed that the peak load of the specimen was increased as increase in clay percentage from $1 \%$ to $5 \%$. The use of nano composites increases the bending strength up to $47 \%$ as compared to virgin epoxy.

After the initial bending test effect of natural degradation was calculated, specimens were dipped in a water bath for 15 days and were subjected to three point bending test.

Table -2: Natural degradation of specimens

\begin{tabular}{|l|l|l|l|}
\hline $\begin{array}{l}\text { Clay } \\
\text { loading }\end{array}$ & $\begin{array}{l}\text { Initial } \\
\text { bending } \\
\text { strength } \\
\text { (MPa) }\end{array}$ & $\begin{array}{l}\text { Bending } \\
\text { strength } \\
\text { after } \\
\text { days } \\
(\mathrm{MPa})\end{array}$ & $\begin{array}{l}\text { \% } \\
\text { Decrease in } \\
\text { bending } \\
\text { strength }\end{array}$ \\
\hline $0 \%$ & 4.8048 & 4.1428 & 13.77 \\
\hline $1 \%$ & 5.5209 & 5.0358 & 8.787 \\
\hline $3 \%$ & 6.237 & 5.9136 & 5.185 \\
\hline $5 \%$ & 7.101 & 6.80 & 4.238 \\
\hline
\end{tabular}

The results of the specimens before and after exposure are equated it has been found that the degradation in the samples without the clay is more as compared to the specimens with modified epoxy with nanoclay. The face sheets with nanoclay is offering barrier to the water. The bending strength reduced from 4.8048 to 4.1428 there was 
in total $13 \%$ reduction in the strength for composite with neat epoxy. The modified epoxy specimens showed less reduction in the strength after degradation and specimen with $5 \%$ nanoclay particles showed the best result during the natural degradation.

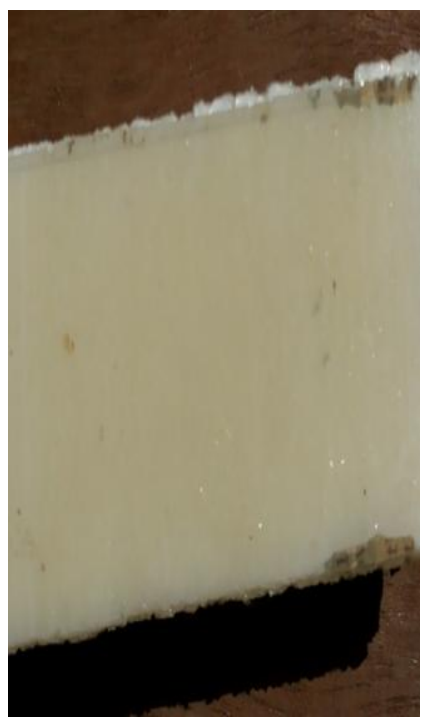

(a)

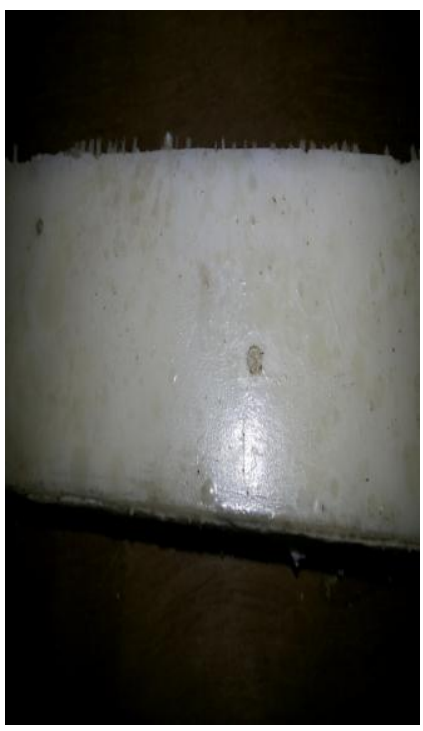

(b)

Fig-6: (a) Shiny Surface before Exposure; (b) Scale formation after exposure

After 15 days there was some scale formation on the specimen, with water immersed specimen. Surface observation showed that due to scale formation the epoxy had lost some shine on either side as shown in figure 6 . But still after bending (by hands) the epoxy showed considerable strength and flexibility.

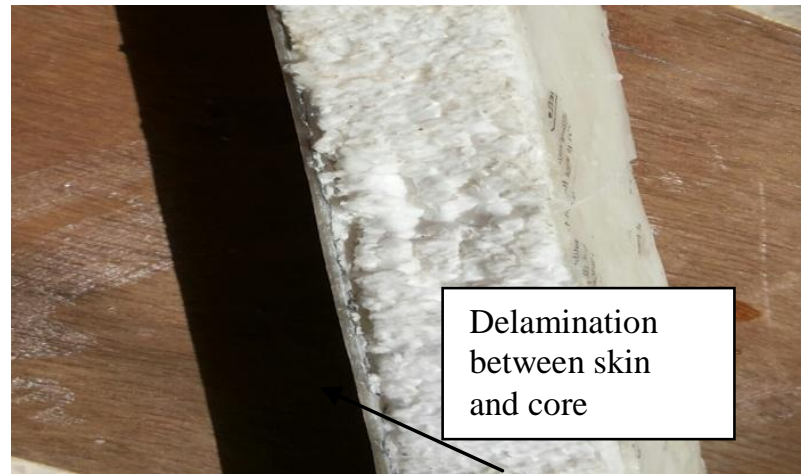

Fig-7: Delamination of sheets after Exposure

As per visual observation of specimen, it was observed that core cracking and delamination occurred in thermocol sheet during the flexural testing. Degradation in thermocol was observed which is clearly visible in figure 7 shear cracks and core crushing were observed. These defects affect the strength and durability of sandwich composite structures. Epoxy cracking was also observed in some portions.

Weight gains were indicated by periodic removal of the specimens from the water bath and weighing on a digital balance. The specimens of various clay loadings were immersed in water at environmental temperature. Figure 8 shows the increase in weight percentage with respect to number of days.

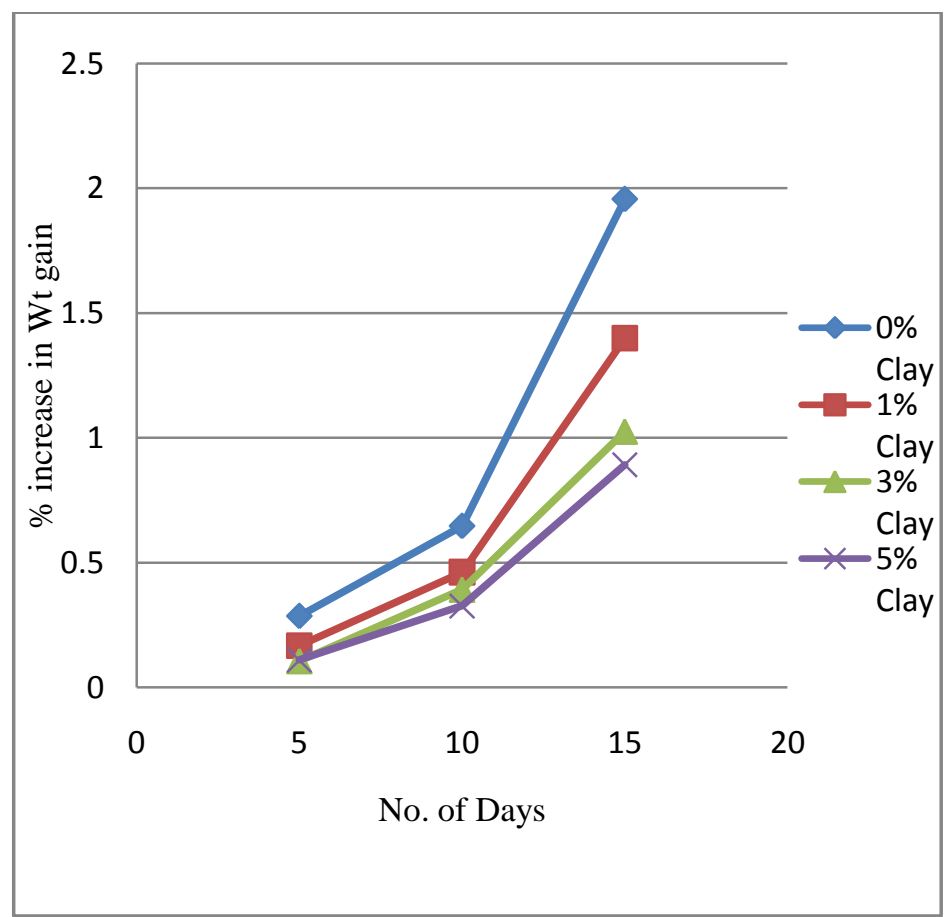

Fig-8: Percentage Weight gain versus No. of days

Table - 3: Percentage weight gain of specimens after

\begin{tabular}{|l|l|l|l|l|l|}
\hline $\begin{array}{l}\text { Clay } \\
\text { loading }\end{array}$ & $\begin{array}{l}\text { Initial } \\
\text { weight }\end{array}$ & $\begin{array}{l}\text { Weight } \\
\text { after 5 } \\
\text { days }\end{array}$ & $\begin{array}{l}\text { Weight } \\
\text { after 10 } \\
\text { days }\end{array}$ & $\begin{array}{l}\text { Weight } \\
\text { after 15 } \\
\text { days }\end{array}$ & $\begin{array}{l}\% \\
\text { weight } \\
\text { gain }\end{array}$ \\
\hline $0 \%$ & 64.746 & 65.10 & 66.013 & 66.801 & 3.174 \\
\hline
\end{tabular}




\begin{tabular}{|l|l|l|l|l|l|}
\hline $1 \%$ & 66.201 & 66.507 & 67.127 & 67.612 & 2.131 \\
\hline $3 \%$ & 76.140 & 76.347 & 76.921 & 77.55 & 1.852 \\
\hline $5 \%$ & 75.355 & 75.601 & 76.027 & 76.59 & 1.641 \\
\hline
\end{tabular}

It is very much clear from the table 3 and figure 8 that the maximum weight gain percentage is shown by the sample of without nanoclay loading. There is weight gain for other specimens also but it is less comparative to neat epoxy specimen showing less water intake.

\section{CONCLUSIONS}

The hand layup method was used for the manufacturing of composites and characterization was performed using SEM and XRD. The results show that the polymer intercalated in the layered silicates increasing the D-spacing from $18 \AA$ to $32.32 \AA$. The SEM micrographs showed that the proper dispersion but agglomerates were visible in $5 \%$ clay loading.

The tensile strength increased $33 \%$ by the addition of nanoclay particles in epoxy. The maximum tensile strength is attained by using $3 \%$ of clay and further addition reduced the strength. After natural degradation there was some reduction in the peak loads and corresponding bending strength. The specimen with neat epoxy showed the maximum degradation up to $13 \%$ and it was less in case of specimens with nanocomosite sheets. The water resistance property of epoxy was improved by the addition of both glass fibre and nanoclay, which is maybe attributed to the increasing of the tortuosity path for water penetration. Three point bending test performed after the exposure to water showed shear cracks and delamination of sheets and core. There was scale formation on the surface after natural degradation. The percentage weight gain was highest in the case of neat epoxy it was $4 \%$ but it was less when epoxy was modified with nanoclay.

\section{REFERENCES}

[1]. Zenkert D., Ed. (1997), The Handbook of Sandwich Construction. London: Engineering Materials Advisory Services Ltd.

[2]. Sushma Singh, (2010), Strength degradation of glass fibre reinforced polymer sandwich composites under hygrothermal loading conditions. http://dspace.thapar.edu:8080/dspace/bitstream/10266/1351/ 1/SUSHMA.pd $\mathrm{f}$

[3]. Jatin M. Patel, B A Modi (2013), Stiffness and Thermal Analysis of Doubly Curve Sandwich Panel for an Automobile Application Procedia Engineering 51, 655 664.

[4]. Rajmohan T, Koundinya U.K, Arun Premnath, Harish G (2013), Evaluation of Mechanical Properties of Nano Filled Glass Fiber Reinforced 978-1-4799- 1379-4/13 IEEE.

[5]. Jumahat A, Soutis c, Mahmud J, Ahmad N (2012), Compressive properties of nanoclay/epoxy nanocomposites. Science direct Procedia Engineering, 41, 1607-1613.
[6]. Sharma B, Mahajan S, Chhibbe r R, Mehta R (2012), Glass Fiber Reinforced Polymer-Clay Nanocomposites: Processing, Structure and Hygrothermal Effects on Mechanical Properties. Sciencedirect Procedia Chemistry 4, $39-46$.

\section{BIOGRAPHIES}

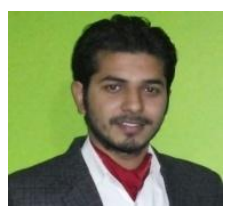

Shivraj Puggal, a Lecturer at Lovely Professional University with an experience of 3 years, worked on Nanocomposites

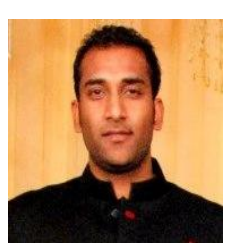

Sumit Mahajan, a Assistant Professor at Lovely Professional University with an experience of 3 years, worked on Nanocomposites

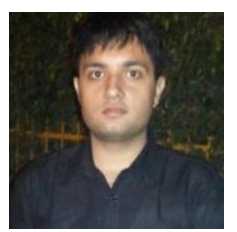

Novepreet Dhall, a Lecturer at Lovely Professional University with an experience of 3 years, worked on Nanocomposites 